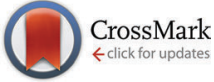

Cite this: Phys. Chem. Chem. Phys. 2016, 18, 23864

Received 9th June 2016 Accepted 10th August 2016

DOI: $10.1039 / c 6 c p 04011 j$

www.rsc.org/pccp

\title{
CoP for hydrogen evolution: implications from hydrogen adsorption $\dagger$
}

\begin{abstract}
Guoxiang Hu, Qing Tang and De-en Jiang*
Cobalt phosphide (CoP) is one of the most promising, earth-abundant electrocatalysts discovered to date for hydrogen evolution reaction (HER), yet the mechanism is not well understood. Since hydrogen adsorption is a key factor of HER activity, here we examine the adsorption of atomic hydrogen on the low-Miller-index surfaces of CoP, including (111), (110), (100), and (011), by using periodic density functional theory. From the calculated Gibbs free energy of adsorption, we predict that (111), (110), and (011) surfaces will have good catalytic activities for HER. From ab initio atomistic thermodynamics, we find that the stabilities of the surfaces at $1 \mathrm{~atm} \mathrm{H}_{2}$ and $300 \mathrm{~K}$ follow the trend of (111) > (100) (110) 》 (011). On the most stable (111) surface, both Co bridge sites and $\mathrm{P}$ top sites are found to be able to adsorb hydrogen with a close-to-zero free energy change and the synergy of proximal Co and $\mathrm{P}$ atoms on the surface results in a better HER activity. Our work provides important insights into CoP's excellent HER activity and a basis for further mechanistic understanding of HER on COP and other transition-metal phosphides.
\end{abstract}

\section{Introduction}

Water splitting using renewable energy can provide a sustainable supply of fuel for future societies with hydrogen as a key energy carrier. ${ }^{1}$ To date, platinum remains the most efficient electrocatalyst for hydrogen evolution reaction (HER). However, the low natural abundance and high cost of platinum hamper its wide use at the industrial scale. Thus, it is highly desirable to develop efficient, low-cost and earth-abundant electrocatalysts for HER and an enormous amount of research efforts have been devoted to it over the past decade.

Transition metal phosphides have emerged as alternative materials for HER electrocatalysts due to their high catalytic activities compared to other non-precious electrocatalysts and their relatively low costs compared to platinum. For example,

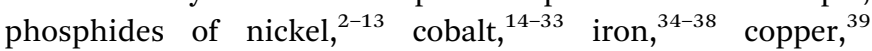
molybdenum, ${ }^{40-45}$ and tungsten ${ }^{46}$ have been found to electrocatalytically generate hydrogen with low overpotentials at operationally relevant current densities. In particular, the cobalt phosphide system, which has been studied extensively, exhibits high HER activities and high stabilities under strongly acidic conditions across a diverse group of morphologies, characteristic grain sizes, support materials, and synthetic preparations. Among these systems, multi-faceted single-crystalline cobalt phosphide

Department of Chemistry, University of California, Riverside, CA 92521, USA.

E-mail: de-en.jiang@ucr.edu

$\dagger$ Electronic supplementary information (ESI) available. See DOI: 10.1039/ c6cp04011j
(CoP) nanoparticles deposited on a titanium foil electrode exhibit outstanding activities, with overpotentials of only -70 and $-85 \mathrm{mV}$ (at a loading density of $\sim 2 \mathrm{mg} \mathrm{cm}^{-2}$ ) to produce cathodic current densities of -10 and $-20 \mathrm{~mA} \mathrm{~cm}^{-2}$, respectively. ${ }^{14}$ Despite the exciting experimental results of $\mathrm{CoP}$, the mechanism of HER on $\mathrm{CoP}$ is not well understood, which is essential for further improving the activities and stabilities of the HER electrocatalysts.

Two types of possible pathways have been proposed for the mechanism of HER in acid media: the Volmer-Heyrovsky $v s$. the Volmer-Tafel mechanism. The Volmer reaction refers to the initial adsorption of protons from the acid solution to form adsorbed $\mathrm{H}\left(\mathrm{H}^{+}+\mathrm{e}^{-} \rightarrow \mathrm{H}_{\mathrm{ad}}\right) \cdot{ }^{47}$ In the Volmer-Heyrovsky mechanism, a solvated proton from the water layer reacts with one adsorbed surface hydrogen to form $\mathrm{H}_{2}\left(\mathrm{H}_{\mathrm{ad}}+\mathrm{H}^{+}+\mathrm{e}^{-} \rightarrow \mathrm{H}_{2}\right){ }^{48}$ while in the Volmer-Tafel mechanism, two adsorbed surface hydrogens next to each other react to form an $\mathrm{H}_{2}$ molecule $\left(\mathrm{H}_{\mathrm{ad}}+\mathrm{H}_{\mathrm{ad}} \rightarrow \mathrm{H}_{2}\right) .{ }^{49}$ Thus, good HER electrocatalysts should be able to attract protons from the solution, while still can desorb $\mathrm{H}_{2}$. Nørskov and coworkers have correlated experimental exchange currents with calculated hydrogen adsorption energies from density functional theory (DFT), where maximum activity is obtainable when Gibbs free energy of hydrogen adsorption $\left(\Delta G_{\mathrm{H}}\right)$ is zero. ${ }^{50}$ This is mainly because lower $\Delta G_{\mathrm{H}}$ results in a very strong binding of the atomic hydrogen and hinders desorption of $\mathrm{H}_{2}$, while higher $\Delta G_{\mathrm{H}}$ prevents the binding of atomic hydrogen on the catalyst surfaces. Both of them will slow the reaction. Therefore, $\Delta G_{\mathrm{H}}$ is considered as a good descriptor of HER activity, and good HER electrocatalysts are expected to have close-to-zero $\Delta G_{\mathrm{H}}$. 
To understand HER on CoP in particular and to provide insights and guidelines for designing transition metal phosphide HER electrocatalysts in general, herein we have studied in detail the adsorption structures and energetics of atomic hydrogen on several low-Miller-index surfaces of CoP from first principles DFT. We use the calculated $\Delta G_{\mathrm{H}}$ to predict the HER activities of the surfaces. We further employ $a b$ initio atomistic thermodynamics to determine the most stable and active surface of $\mathrm{CoP}$ at $1 \mathrm{~atm} \mathrm{H}_{2}$ pressure and $300 \mathrm{~K}$.

\section{Computational}

Spin-polarized DFT calculations were performed by using the Vienna $a b$ initio simulation package (VASP). ${ }^{51}$ The ion-electron interaction was described with the projector augmented wave (PAW) method. ${ }^{52}$ Electron exchange-correlation was represented by the functional of Perdew, Burke and Ernzerhof (PBE) of generalized gradient approximation (GGA). ${ }^{53}$ A cutoff energy of $400 \mathrm{eV}$ was used for the plane-wave basis set. (111), (110), (100), and (011) surfaces were examined. About $10 \AA$ thick slabs in $(2 \times 2)$ lateral cells with $15 \AA$ of vacuum along the $z$-direction were used to model the adsorbate-surface systems for (111), (110), (100), and (011) surfaces; the Brillouin zone was sampled by $(3 \times 3 \times 1)$ Monkhorst-Pack $k$-point mesh. Both the layer thickness and $k$-point mesh were tested to achieve a convergence of hydrogen adsorption energy within $0.04 \mathrm{eV}$. The top half of the slab was allowed to relax together with the adsorbed $\mathrm{H}$ atoms and the convergence threshold for structural optimization was set to be $0.025 \mathrm{eV} \AA^{-1}$ in force. Partial atomic charges were obtained using Bader charge analysis as implemented by Henkelman and co-workers. ${ }^{54}$ We also used a different method ${ }^{55}$ to derive the atomic charges based on the electrostatic potential, called the ESP charges.

Surface energies was determined by using

$$
\gamma=\frac{E_{\text {slab }}-N E_{\text {bulk }}}{2 A}
$$

where $E_{\text {slab }}$ is the total energy of the surface slab, $E_{\text {bulk }}$ is the total energy of the bulk unit cell (eV per CoP), $N$ is the number of unit formula in the slab, and $A$ is the surface area. The differential hydrogen adsorption energy $\Delta E_{\mathrm{H}}$ was calculated by

$$
\Delta E_{\mathrm{H}}=E(\mathrm{CoP}+n \mathrm{H})-E[\mathrm{CoP}+(n-1) \mathrm{H}]-\frac{1}{2} E\left(\mathrm{H}_{2}\right)
$$

where $E(\mathrm{CoP}+n \mathrm{H})$ and $E[\mathrm{CoP}+(n-1) \mathrm{H}]$ represent the total energy of the CoP system with $n$ and $n-1$ adsorbed hydrogen atoms on the surface, respectively, and $E\left(\mathrm{H}_{2}\right)$ represents the total energy of a gas phase $\mathrm{H}_{2}$ molecule. A negative value of $\Delta E_{\mathrm{H}}$ suggests favorable absorption. The differential Gibbs free energy of adsorption $\Delta G_{\mathrm{H}}$ was obtained by

$$
\Delta G_{\mathrm{H}}=\Delta E_{\mathrm{H}}+\Delta E_{\mathrm{ZPE}}-T \Delta S_{\mathrm{H}}
$$

where $\Delta E_{\mathrm{ZPE}}$ is the difference in zero point energy between the adsorbed $\mathrm{H}$ and $\mathrm{H}$ in the gas phase $\mathrm{H}_{2}$ molecule, and $\Delta S_{\mathrm{H}}$ is the entropy difference between the adsorbed $\mathrm{H}$ and $\mathrm{H}_{2}$ in the gas phase at standard conditions. To locate the most stable configuration for each coverage of $\mathrm{H}$ on a surface, we allowed the $\mathrm{H}$ atoms to first find the lowest energy sites and then fill the next lowest-energy sites and continue until the desired coverage was reached. In other words, we focused on finding the global minimum of hydrogen adsorption, with an assumption that the diffusion of $\mathrm{H}$ atoms on the surface would be facile and they always go to the lowest-energy sites.

$A b$ initio atomistic thermodynamics ${ }^{56}$ was used to identify the most stable phase of each surface at $1 \mathrm{~atm} \mathrm{H}_{2}$ and $300 \mathrm{~K}$. The Gibbs free energy of adsorption at a specific temperature and pressure $\Delta G^{\mathrm{ad}}(T, p)$ was calculated by

$$
\Delta G^{\mathrm{ad}}(T, p)=\frac{1}{A}\left[E^{\mathrm{total}}\left(N_{\mathrm{H}}\right)-E^{\mathrm{total}}(0)-\frac{N_{\mathrm{H}}}{2} E_{\mathrm{H}_{2}}^{\mathrm{total}}-N_{\mathrm{H}} \Delta \mu_{\mathrm{H}}(T, p)\right]
$$

where $E^{\text {total }}\left(N_{\mathrm{H}}\right)$ is the total energy of the CoP system with $N_{\mathrm{H}}$ hydrogen atoms adsorbed on the surface, $E^{\text {total }}(0)$ is the total energy of the clean CoP surface, and $E_{\mathrm{H}_{2}}^{\text {total }}$ is the total energy of a gas phase $\mathrm{H}_{2}$ molecule. $\Delta \mu_{\mathrm{H}}(T, p)$ is the chemical potential of hydrogen at different temperatures and pressures. Eqn (4) allows one to plot the Gibbs free energy of adsorption as a function of the hydrogen chemical potential for a specific surface at a specific $\mathrm{H}$ coverage. At any given hydrogen chemical potential, the stability of these $\mathrm{H}$-covered surfaces can then be compared. $\Delta \mu_{\mathrm{H}}(T, p)$ is related to specific $(T, p)$-conditions by

$$
\Delta \mu_{\mathrm{H}}(T, p)=\Delta \mu_{\mathrm{H}}\left(T, p^{0}\right)+\frac{1}{2} k_{\mathrm{B}} T \ln \left(\frac{p}{p^{0}}\right)
$$

where $\Delta \mu_{\mathrm{H}}\left(T, p^{0}\right)$ is the hydrogen chemical potential at the standard pressure which can be looked up from the thermodynamic tables. ${ }^{57}$

\section{Results and discussion}

We start with the bulk structure of CoP, followed by the clean surfaces including (111), (110), (100), and (011). We then examine and compare hydrogen adsorption on these surfaces.

\section{Bulk CoP}

Bulk CoP has a B31 or MnP-type structure, with a symmetry group of Pnma. In this type of structure, each metal atom is surrounded by six phosphorous atoms situated in a distorted octahedral configuration (Fig. 1a), while each phosphorous atom is surrounded by six metal atoms forming a highly distorted triangular prism (Fig. 1b). The experimental $^{58}$ and calculated lattice parameters of bulk CoP are listed in Table 1 . One can see that they are in good agreement.

\section{Clean surfaces}

Low Miller-index surfaces are usually considered first in surface science studies due to their higher stabilities than higher index surfaces. We consider here four such surfaces: (111), (110), (100), and (011). Fig. 2 shows the structures of these clean CoP surfaces and Table 2 shows their calculated surface energies. One can see 
(a)

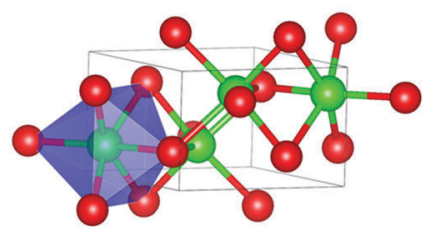

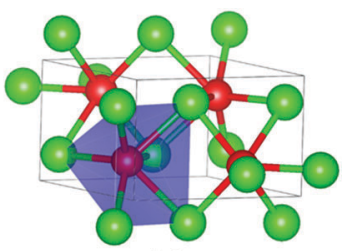

(b)
Fig. 1 Bulk CoP: (a) each Co atom is surrounded by six P atoms situated in a distorted octahedral configuration; (b) each $\mathrm{P}$ atom is surrounded by six $\mathrm{Co}$ atoms at the corners of a highly distorted triangular prism. Co, green; $P$, red.

Table 1 Comparison of experimental ${ }^{58}$ and calculated lattice parameters of the bulk CoP

\begin{tabular}{llll}
\hline Lattice parameter & $a(\AA)$ & $b(\AA)$ & $c(\AA)$ \\
\hline Experimental & 5.077 & 3.281 & 5.587 \\
Calculated & 5.070 & 3.265 & 5.545
\end{tabular}
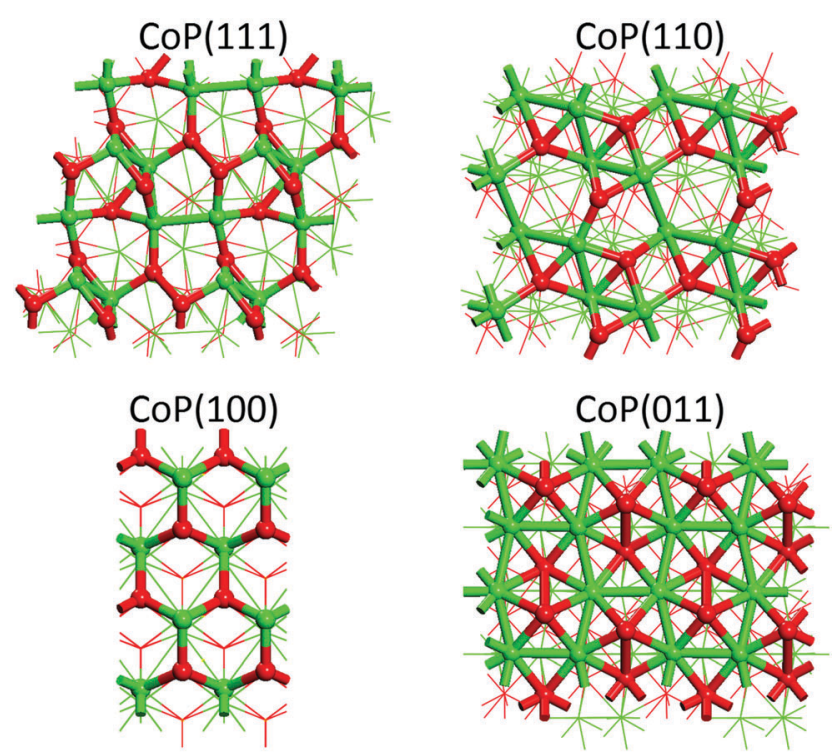

Fig. 2 Top views of clean CoP surfaces. Co, green; P, red.

that the stabilities of the clean surfaces in vacuum follow the trend of $(011)>(110)>(111)>(100)$. In general, surfaces with higher atom packing densities are expected to have higher stabilities. Here, we find that the surface packing densities of (011), (110), (111), and (100) are 25, 24, 24, and 22 atom per $\mathrm{nm}^{2}$, respectively, which indeed confirms the highest stability of the (011) surface and the lowest stability of the (100) surface. To learn the electronic structures of these surfaces, their electronic density of states (DOS) have been calculated. As shown in Fig. 3, they are all metallic and have non-zero DOS at the Fermi level. Being the

Table 2 Calculated surface energies of clean CoP surfaces

\begin{tabular}{lllll}
\hline & $\operatorname{CoP}(111)$ & $\operatorname{CoP}(110)$ & $\operatorname{CoP}(100)$ & $\operatorname{CoP}(011)$ \\
\hline Surface energy $\left(\mathrm{meV} \mathrm{\AA}^{-2}\right)$ & 140.4 & 117.0 & 151.0 & 70.4
\end{tabular}

most stable one, the (011) surface also has the lowest DOS at the Fermi level.

\section{Hydrogen adsorption on the $\operatorname{CoP}(111)$ surface}

As mentioned in the Introduction, $\Delta G_{\mathrm{H}}$ is considered as a descriptor of HER activity, and good HER electrocatalysts should have close-to-zero $\Delta G_{\mathrm{H}}$. We next show the structures and $\Delta G_{\mathrm{H}}$ of $\mathrm{H}$ adsorption on the four CoP surfaces. Fig. 4 shows the calculated $\Delta G_{\mathrm{H}}$ and $\Delta E_{\mathrm{H}}$ for $\operatorname{CoP}(111)$ at different hydrogen coverages (here $100 \%$ coverage $=11 \mathrm{H}$-atom per $\mathrm{nm}^{2}$ ). $\Delta G_{\mathrm{H}}$ is more positive than $\Delta E_{\mathrm{H}}$ because $\Delta S$ is negative when referencing to the $\mathrm{H}_{2}$ state and the $T \Delta S$ term is roughly constant at $-0.18 \mathrm{eV}$ across the coverage range. One can see that $\Delta G_{\mathrm{H}}$ is close-to-zero for $25-75 \%$ hydrogen coverage, indicating that the (111) surface will have good catalytic activity for HER at this coverage range. This supports the previous experimental finding that CoP nanostructures exposing predominately (111) surface have high HER activities. ${ }^{23}$ The other interesting finding of $\mathrm{H}$ adsorption on $\operatorname{CoP}(111)$ is that $\Delta G_{\mathrm{H}}$ shows a zigzag pattern with $\mathrm{H}$ coverage from $25 \%$ to $75 \%$, which closely correlates with the adsorption sites, as discussed next.

Fig. 5 shows the optimized structures of $\operatorname{CoP}(111)$ with different hydrogen coverages. We find four types of stable hydrogen adsorption sites on $\operatorname{CoP}(111)$. For the first $25 \%$ hydrogen atoms, they are strongly adsorbed at cobalt bridge sites. During $25-75 \%$ hydrogen coverage, there is an alternative adsorption between cobalt bridge sites and phosphorous top sites, leading to a zigzagged $\Delta G_{\mathrm{H}}$ with a small fluctuation. More important, $\Delta G_{\mathrm{H}}$ is close-to-zero during this range, so both cobalt bridge sites and phosphorous top sites could be the active sites for HER on the (111) surface. For the $75 \%$ to $100 \%$ coverage, the extra hydrogen atoms are adsorbed at cobalt top sites, leading to more than one hydrogen atoms on some cobalt atoms.

The "zigzag" pattern between $25 \%$ and $75 \%$ hydrogen coverage suggests a synergy between proximal cobalt and phosphorous sites in adsorbing $\mathrm{H}$ atoms, conductive to HER. To understand this behavior, Table 3 shows differential hydrogen adsorption energies $\left(\Delta E_{\mathrm{H}}\right)$ at the phosphorous top site at $0 \%$ and $31 \%$ hydrogen coverages. One can see that when there is no hydrogen adsorbed on Co ( $0 \%)$, the interaction of $\mathrm{H}$ with $\mathrm{P}$ is weak but when there are hydrogens already adsorbed on Co (31\%), the $\mathrm{H}-\mathrm{P}$ interaction becomes stronger. In other words, hydrogen adsorption at Co facilitates hydrogen adsorption at $\mathrm{P}$. We found that this is due to the weakening of the Co-P bond induced by hydrogen adsorption on $\mathrm{Co}$, as evidenced by the increasing Co-P bond length, which results in less negative charge on $\mathrm{P}$ (both Bader ${ }^{54}$ and $\mathrm{ESP}^{55}$ charges show the same trend) and stronger H-P covalent bonding. This synergy between Co and $\mathrm{P}$ for adsorbing $\mathrm{H}$, as shown in Scheme 1, could be a key to CoP's high HER activity.

To evaluate the most stable coverage of $\mathrm{H}$ on $\operatorname{CoP}(111)$ at the experimental HER conditions ( $1 \mathrm{~atm} \mathrm{H}_{2}$ and $300 \mathrm{~K}$ ), we used ab initio atomistic thermodynamics to determine $\Delta G^{\text {ad }}(T, p)$ as a function of hydrogen chemical potential $\left(\Delta \mu_{\mathrm{H}}\right)$ or pressure at $T=300$ K. Fig. 6 shows the calculated $\Delta G^{\text {ad }}(T, p)$ vs. $\Delta \mu_{\mathrm{H}}$ relationship: each line represents a given $\mathrm{H}$ coverage. One can 

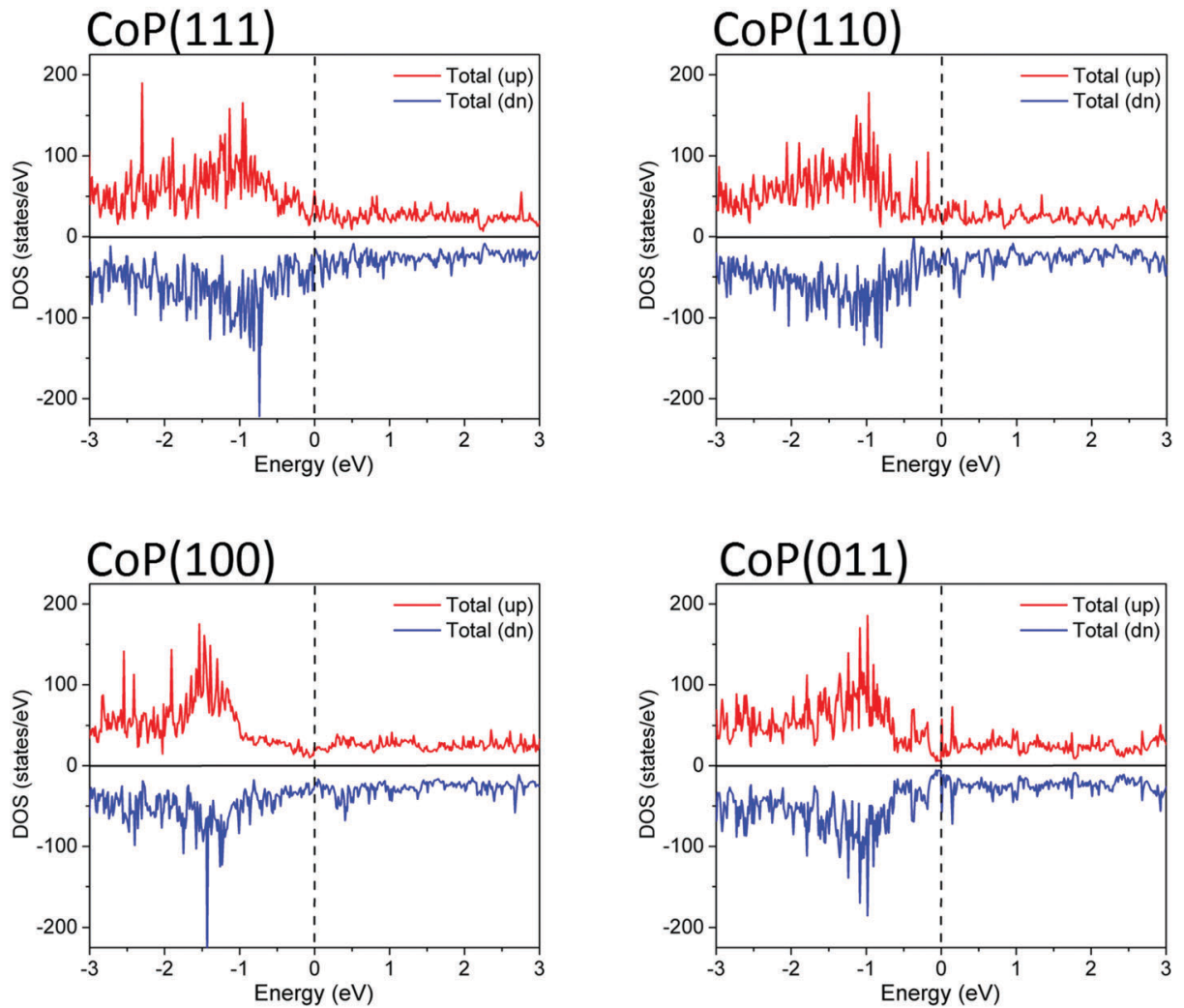

Fig. 3 Spin-polarized total electronic density of states (DOS) of clean CoP surfaces. The Fermi level (dashed line) is set as zero.

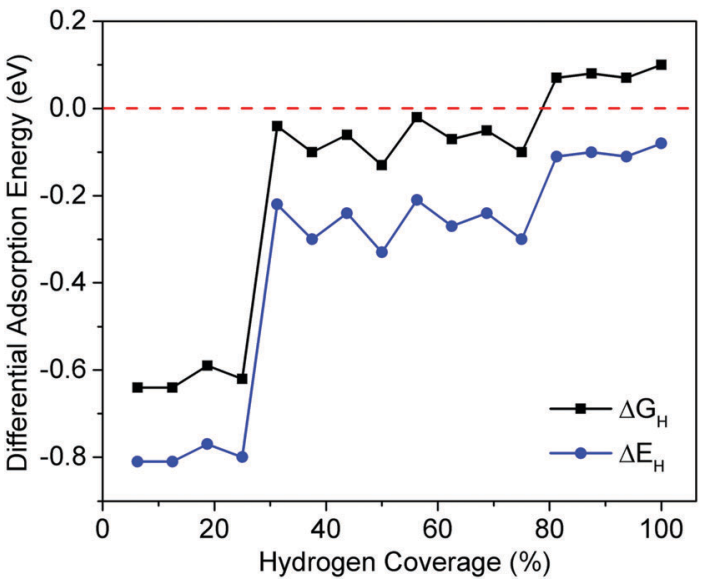

Fig. 4 Differential adsorption energy $\left(\Delta E_{H}\right)$ and adsorption free energy $\left(\Delta G_{H}\right)$ as a function of hydrogen coverage on $\operatorname{CoP}(111)$.

see that at extremely low hydrogen pressure, clean surface is the most stable, while at very high hydrogen pressure, $100 \%$ hydrogen coverage is the most stable (Fig. 6a). At ambient pressures, Fig. $6 \mathrm{~b}$ shows that $75 \%$ hydrogen coverage is the most stable with $\Delta G^{\text {ad }}=-19.53 \mathrm{meV} \AA^{-2}$ at $1 \mathrm{~atm}$. At this coverage, both Co and $\mathrm{P}$ sites adsorb $\mathrm{H}$.

\section{Hydrogen adsorption on the $\operatorname{CoP}(110)$ surface}

Fig. 7 shows $\Delta G_{\mathrm{H}}$ and $\Delta E_{\mathrm{H}}$ for the $\operatorname{CoP}(110)$ surface at different hydrogen coverages $\left(100 \%\right.$ coverage $=12 \mathrm{H}$-atom per $\left.\mathrm{nm}^{2}\right)$.
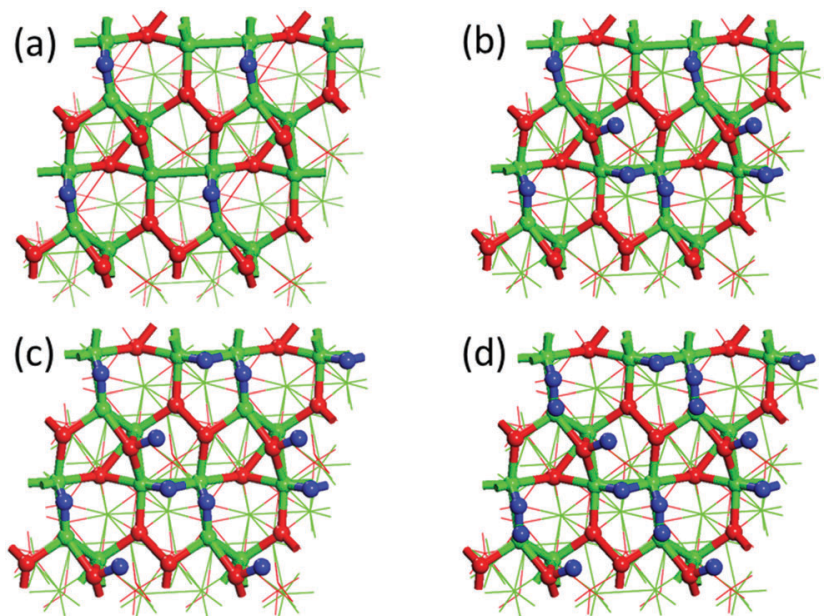

Fig. 5 Optimized structures of $\mathrm{CoP}(111)$ at different $\mathrm{H}$ coverages: (a) 25\%; (b) $50 \%$; (c) $75 \%$; (d) $100 \% .100 \%$ coverage $=11 \mathrm{H}$-atom per $\mathrm{nm}^{2}$. H, blue; Co, green; $P$, red.

For a favorable adsorption $\left(\Delta G_{\mathrm{H}}<0\right)$, we found that $\Delta G_{\mathrm{H}}$ is close to zero when hydrogen coverage is in the range of $25-50 \%$ $\left(\Delta G_{\mathrm{H}} \sim-0.10 \mathrm{eV}\right)$. When hydrogen coverage is above $50 \%, \Delta G_{\mathrm{H}}$ is slightly positive but also close to zero. Fig. 7 suggests that the $\mathrm{CoP}(110)$ surface can also be good for HER activity for a large range of $\mathrm{H}$ coverage. Fig. S1 (ESI $\dagger$ ) shows the optimized structures of $\operatorname{CoP}(110)$ at different hydrogen coverages. From $0 \%$ to $100 \%$ coverage, hydrogen atoms occupy cobalt bridge 
Table 3 Differential hydrogen adsorption energies $\left(\Delta E_{H}\right)$ at the $P$ site, Co-P bond length $\left(r_{\mathrm{Co}-\mathrm{P}}\right)$, and partial atomic charges on $\mathrm{P}$ at $\mathrm{O} \%$ and $31 \%$ hydrogen coverages from Bader analysis $\left(P_{\text {Bader }}\right)$ and electrostatic potential $\left(P_{\mathrm{ESP}}\right)$

\begin{tabular}{lcc}
\hline Hydrogen coverage & $0 \%$ & $31 \%$ \\
\hline$\Delta E_{\mathrm{H}}(\mathrm{eV})$ & -0.10 & -0.30 \\
$r_{\mathrm{Co}-\mathrm{P}}(\AA)$ & 2.125 & 2.197 \\
$P_{\text {Bader }}(|e|)$ & -0.257 & -0.213 \\
$P_{\mathrm{ESP}}(|e|)$ & -0.308 & -0.266
\end{tabular}

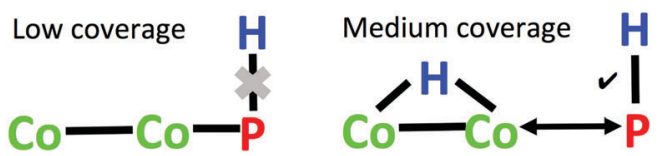

Scheme 1 The synergy between $\mathrm{Co}$ and $\mathrm{P}$ on $\mathrm{CoP}(111)$ in adsorbing $\mathrm{H}$ at medium coverage.

sites, phosphorous top sites, cobalt top sites, and another kind of cobalt top sites successively. Fig. 8 plots $\Delta G^{\text {ad }}$ as a function of $\Delta \mu_{\mathrm{H}}$ for $\mathrm{CoP}(110)$ at different hydrogen coverages. One can see that $50 \%$ hydrogen coverage is the most stable at $1 \mathrm{~atm}$ and $300 \mathrm{~K}$ with $\Delta G^{\text {ad }}=-13.37 \mathrm{meV} \AA^{-2}$. At this coverage, Fig. 7 and Fig. S1 (in the ESI $\dagger$ ) suggest that both the P and Co top sites are most likely to be active for HER.

\section{Hydrogen adsorption on the $\operatorname{CoP}(100)$ surface}

Fig. 9a shows $\Delta G_{\mathrm{H}}$ and $\Delta E_{\mathrm{H}}$ for $\operatorname{CoP}(100)$ at different hydrogen coverages. One can see that there is no $\mathrm{H}$ coverage where $\Delta G_{\mathrm{H}} \sim 0$, so $\operatorname{CoP}(100)$ is not likely to be good for HER. Fig. S2 in $\mathrm{ESI} \dagger$ shows the optimized structures of $\operatorname{CoP}(100)$ with different hydrogen coverages. We find two types of stable hydrogen adsorption sites on $\operatorname{CoP}(100)$ : cobalt bridge sites for the first $33 \%$ hydrogen atoms and cobalt top sites for the following $67 \%$ hydrogen atoms. Unlike (111) and (110) surfaces, only cobalt atoms adsorb hydrogen on the (100) surface.

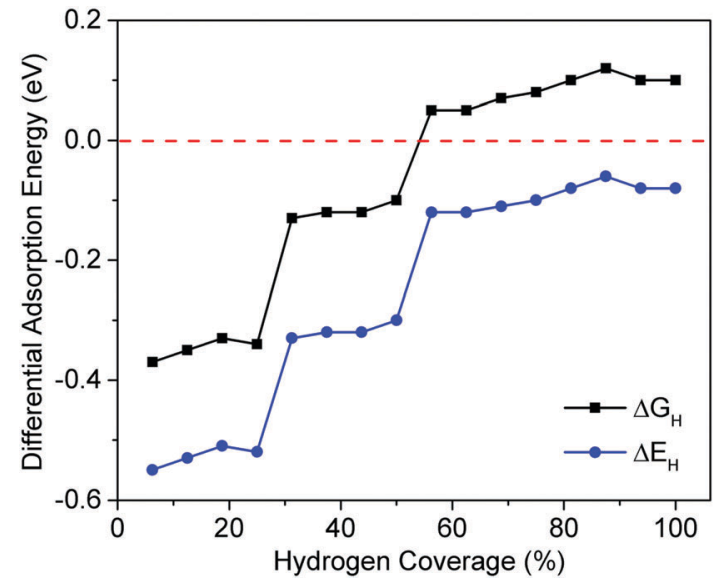

Fig. 7 Differential adsorption energy $\left(\Delta E_{H}\right)$ and adsorption free energy $\left(\Delta G_{H}\right)$ as a function of hydrogen coverage on $\operatorname{CoP}(110)$.

This might be the reason why we do not find $\Delta G_{\mathrm{H}} \sim 0$ on $\operatorname{CoP}(100)$. Fig. 9b plots $\Delta G^{\text {ad }}$ as a function of $\Delta \mu_{\mathrm{H}}$ for $\operatorname{CoP}(100)$ and we find that $33 \%$ hydrogen coverage is the most stable at $1 \mathrm{~atm}$ and $300 \mathrm{~K}$ with $\Delta G^{\text {ad }}=-13.56 \mathrm{meV}^{-2}$.

\section{Hydrogen adsorption on the $\operatorname{CoP}(011)$ surface}

Fig. 10a shows $\Delta G_{\mathrm{H}}$ and $\Delta E_{\mathrm{H}}$ for $\operatorname{CoP}(011)$ at different hydrogen coverages. One can see that the adsorption of $\mathrm{H}$ on $\mathrm{CoP}(011)$ is in general much weaker than on the other three surfaces. On the other hand, this leads to a quite large range of $\mathrm{H}$ coverages from 0 to $50 \%$ where $\Delta G_{\mathrm{H}} \sim 0$, indicating that $\operatorname{CoP}(011)$ may have good activity for HER. Fig. S3 in ESI $\dagger$ shows the optimized structures of $\mathrm{CoP}(011)$ surface at different hydrogen coverages. We find two types of stable hydrogen adsorption sites on $\operatorname{CoP}(011)$. The first $50 \%$ coverage of hydrogen atoms prefer phosphorous top sites with $\Delta G_{\mathrm{H}} \sim 0$, so phosphorous top sites could be the active sites for HER on the (011) surface. This is in agreement with a recent study. ${ }^{33}$ The last $50 \%$ coverage of

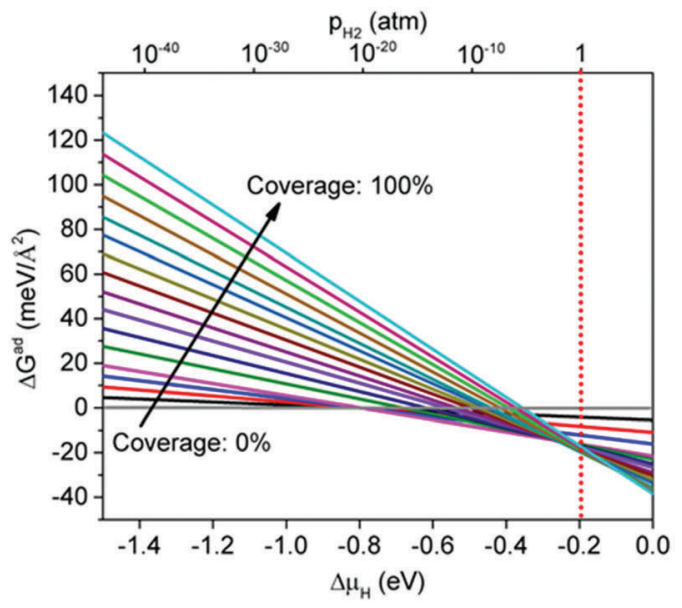

(a)

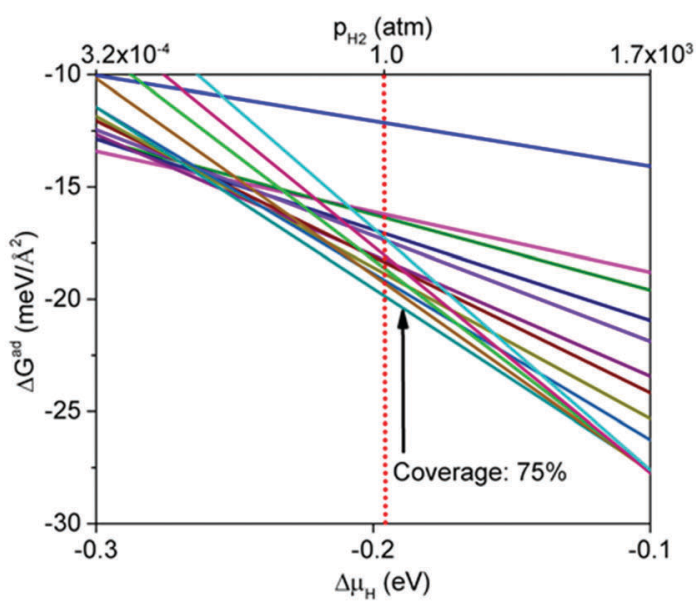

(b)

Fig. 6 Gibbs free energy of adsorption $\left(\Delta G^{\text {ad }}\right)$ at $300 \mathrm{~K}$ as a function of hydrogen chemical potential $\left(\Delta \mu_{H}\right)$ or $\mathrm{H}_{2}$ pressure for CoP(111) with different hydrogen coverages: (a) $\Delta \mu_{H}$ from -1.5 to $0 \mathrm{eV}$; (b) $\Delta \mu_{H}$ from -0.3 to $-0.1 \mathrm{eV}$. 


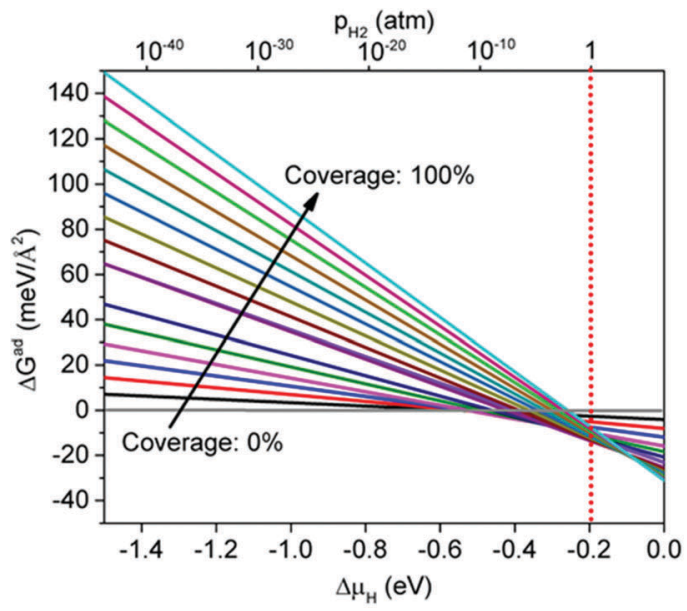

(a)

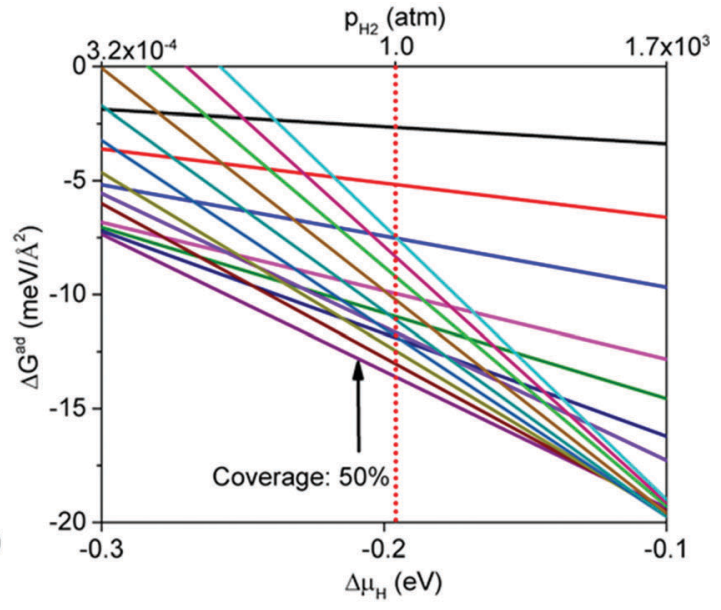

(b)

Fig. 8 Gibbs free energy of adsorption $\left(\Delta G^{\text {ad }}\right)$ at $300 \mathrm{~K}$ as a function of hydrogen chemical potential $\left(\Delta \mu_{H}\right)$ or $\mathrm{H}_{2}$ pressure for CoP(110) with different hydrogen coverages: (a) $\Delta \mu_{\mathrm{H}}$ from -1.5 to $0 \mathrm{eV}$; (b) $\Delta \mu_{\mathrm{H}}$ from -0.3 to $-0.1 \mathrm{eV}$.

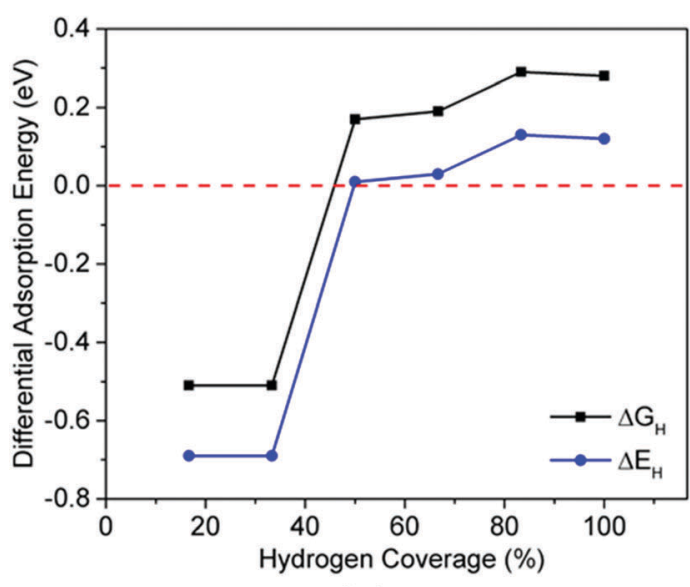

(a)

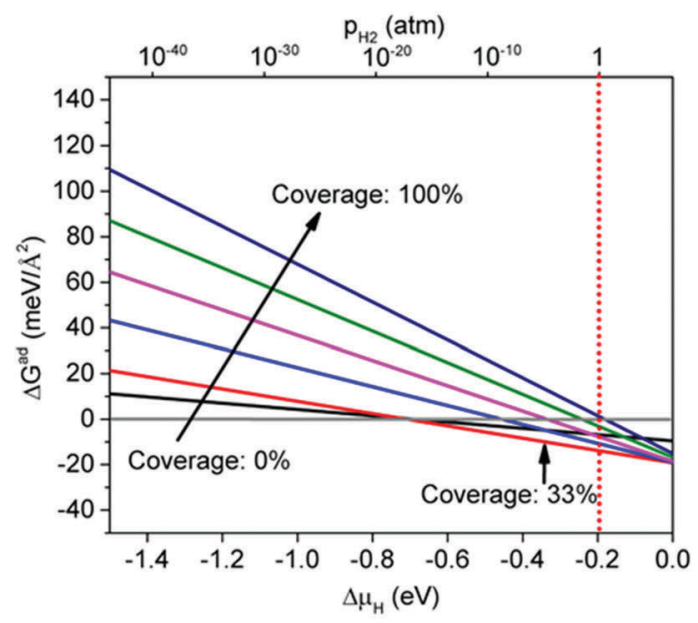

(b)

Fig. 9 (a) Differential adsorption energy $\left(\Delta E_{H}\right)$ and adsorption free energy $\left(\Delta G_{H}\right)$ as a function of hydrogen coverage on CoP(100). (b) Plots of the calculated Gibbs free energy of adsorption $\left(\Delta G^{\text {ad }}\right)$ at $300 \mathrm{~K}$ as a function of hydrogen chemical potential $\left(\Delta \mu_{H}\right)$ for CoP $(100)$ surface with different hydrogen coverages.

hydrogen atoms occupy cobalt bridge sites. Fig. $10 \mathrm{~b}$ plots $\Delta G^{\text {ad }}$ as a function of $\Delta \mu_{\mathrm{H}}$ for $\operatorname{CoP}(011)$ at different hydrogen coverages. One can see that $25 \%$ hydrogen coverage is the most stable phase at $1 \mathrm{~atm}$ and $300 \mathrm{~K}$ with $\Delta G^{\mathrm{ad}} \sim 0 \mathrm{meV} \AA^{-2}$, while the clean surface is only slightly higher in energy. This again agrees with the fact that the adsorption of $\mathrm{H}$ on $\mathrm{CoP}(011)$ is rather weak.

\section{Comparison of (111), (110), (100), and (011) surfaces of CoP}

Now that we have studied hydrogen adsorption on the four low Miller-index surfaces of CoP, we can compare them together in terms of stability and HER activity. Using $\Delta G_{\mathrm{H}} \sim 0$ as a criterion, we predict that (111), (110), and (011) surfaces of CoP should have good catalytic activities for HER, while (100) should not. Taking into account $a b$ initio atomistic thermodynamics, Table 4 shows the comparison of $\Delta G^{\text {ad }}$ at 1 atm $\mathrm{H}_{2}$ and $300 \mathrm{~K}$ for the most stable coverage of each surface. One can see that $\operatorname{CoP}(111)$ has the most negative $\Delta G^{\text {ad }}$ followed by (100) and (110), while (011) has a close-to-zero $\Delta G^{\text {ad }}$. In other words, at the reaction conditions, the stability trend is $(111)>(100) \sim$ (110) 》 (011). From this perspective, we think that the CoP(111) surface is the most promising facet for high-activity HER.

Our present DFT study of the adsorption of atomic hydrogen on the low-Miller-index surfaces of CoP, including (111), (110), (100), and (011), presents several interesting implications. First, CoP nanostructures that expose different crystal facets would be expected to exhibit different activities for HER catalysis. From our calculated $\Delta G_{\mathrm{H}}$, we predict that (111), (110), and (011) surfaces of CoP will have good catalytic activities for HER. So experimental researchers could prepare highly branched nanostructures that expose a high density of these surfaces. Second, both Co and P on the surfaces play important roles in catalyzing HER. Particularly, on (111) surface, both Co bridge 


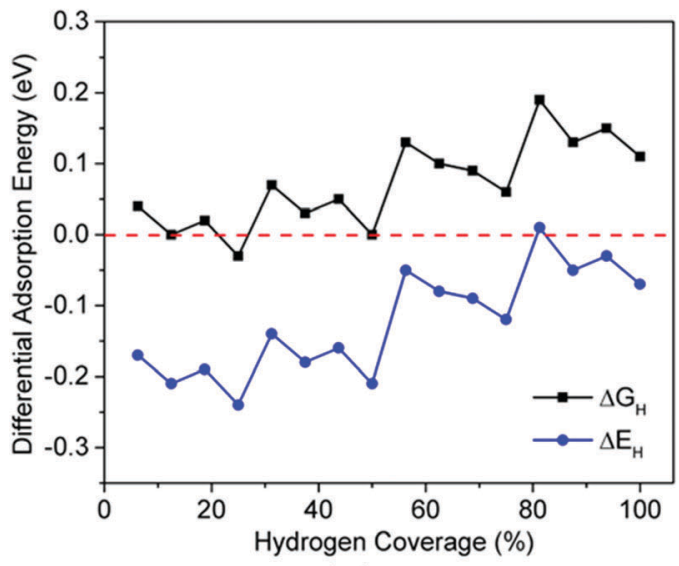

(a)

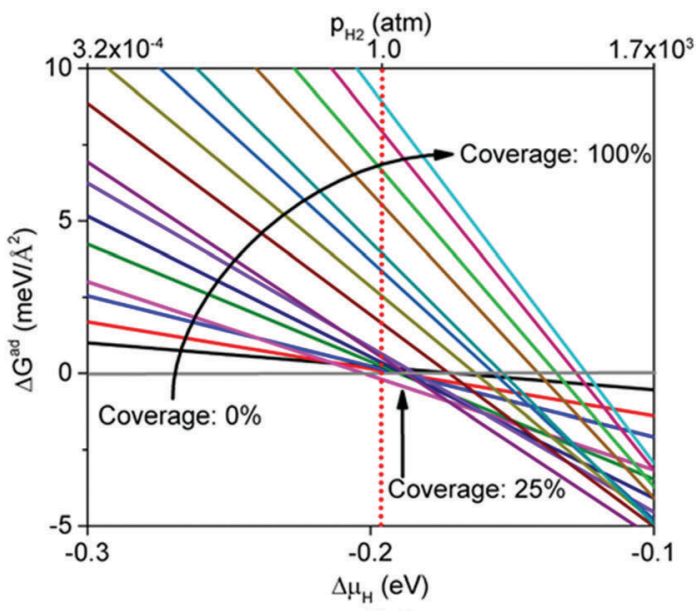

(b)

Fig. 10 (a) Differential adsorption energy $\left(\Delta E_{H}\right)$ and adsorption free energy $\left(\Delta G_{H}\right)$ as a function of hydrogen coverage on CoP(111). (b) Gibbs free energy of adsorption ( $\left.\Delta G^{\text {ad }}\right)$ at $300 \mathrm{~K}$ as a function of hydrogen chemical potential $\left(\Delta \mu_{\mathrm{H}}\right)$ or $\mathrm{H}_{2}$ pressure for $\mathrm{CoP}(011)$ with different hydrogen coverages.

Table 4 Hydrogen adsorption free energies $\left(\Delta G^{\text {ad }}\right)$ at $1 \mathrm{~atm}$ and $300 \mathrm{~K}$ of the most stable coverage for each CoP surface

\begin{tabular}{lllll}
\hline & $\operatorname{CoP}(111)$ & $\operatorname{CoP}(110)$ & $\operatorname{CoP}(100)$ & $\operatorname{CoP}(011)$ \\
\hline$\Delta G^{\mathrm{ad}}\left(\mathrm{meV}^{-2}\right)$ & -19.53 & -13.37 & -13.56 & -0.08
\end{tabular}

sites and $\mathrm{P}$ top sites are found to be able to adsorb hydrogen with a close-to-zero free energy change, indicating that the synergy of proximal Co and $\mathrm{P}$ atoms on the surface can result in a better HER activity. Third, hydrogen coverage, pressure, and temperature all have effects on the stabilities of the surfaces. We find that the stabilities of the clean surfaces in vacuum are different from the stabilities at $1 \mathrm{~atm} \mathrm{H}_{2}$ and $300 \mathrm{~K}$. The stabilities of the clean surfaces in vacuum follow the trend of $(011)>(110)>(111)>(100)$, while the stabilities of the surfaces at $1 \mathrm{~atm} \mathrm{H}_{2}$ and $300 \mathrm{~K}$ follow the trend of (111) > (100) $\sim(110) \gg(011)$. This suggests that if one purposefully prepares the catalyst with the (111) facet, then the catalyst is likely to have a longer lifetime given its high stability during the reaction conditions, while the (011) surface might transform to other more stable surfaces under reaction conditions.

Although the present work focuses on the thermodynamics of HER on different CoP surfaces from computed $\mathrm{H}$ adsorption free energy, our results also have interesting implications for the reaction rates. For example, $75 \%$ coverage of hydrogen on $\operatorname{CoP}(111)$ would be very helpful for the Volmer-Tafel mechanism, as higher surface coverage would increase the chances for two adsorbed hydrogens next to each other to react and form an $\mathrm{H}_{2}$ molecule. We plan to study the detailed mechanism of HER on CoP surfaces to examine the effect of coverage on reaction kinetics, as recently done for HER on $\mathrm{MoS}_{2}{ }^{59}$

\section{Conclusions}

To shed light on the activity of hydrogen evolution reaction (HER) on CoP, we have studied the adsorption of atomic hydrogen on the
low-Miller-index surfaces of CoP, including (111), (110), (100), and (011), by using periodic DFT. From the calculated $\Delta G_{\mathrm{H}}$, we predict that (111), (110), and (011) surfaces will have good catalytic activities for HER. From $a b$ initio atomistic thermodynamics, we find that the stabilities of the surfaces at $1 \mathrm{~atm} \mathrm{H}_{2}$ and $300 \mathrm{~K}$ follow the trend of (111) $>(100) \sim(110) \gg(011)$. So combining $\Delta G_{\mathrm{H}}$ and stability, we conclude that the (111) surface of $\mathrm{CoP}$ is the most promising facet for high and long-lived HER activity. The key feature of hydrogen adsorption on the (111) is that both Co bridge sites and P top sites are able to adsorb hydrogen with a close-to-zero free energy change and that there is a synergy of proximal Co and $\mathrm{P}$ atoms on the $\operatorname{CoP}(111)$ surface in adsorbing hydrogen. These insights open a door for further mechanistic understanding of HER on CoP and other phosphides.

\section{Acknowledgements}

This work was supported by the University of California, Riverside. G. H. thanks Dr Ziqi Tian for help with calculation of ESP charges. This research used resources of the National Energy Research Scientific Computing Center, a DOE Office of Science User Facility supported by the Office of Science of the U.S. Department of Energy under Contract DE-AC02-05CH11231.

\section{References}

1 W. Lubitz and W. Tumas, Chem. Rev., 2007, 107, 3900-3903. 2 P. Liu and J. A. Rodriguez, J. Am. Chem. Soc., 2005, 127, 14871-14878.

3 E. J. Popczun, J. R. McKone, C. G. Read, A. J. Biacchi, A. M. Wiltrout, N. S. Lewis and R. E. Schaak, J. Am. Chem. Soc., 2013, 135, 9267-9270.

4 L. Feng, H. Vrubel, M. Bensimon and X. Hu, Phys. Chem. Chem. Phys., 2014, 16, 5917-5921.

5 Z. Huang, Z. Chen, Z. Chen, C. Lv, H. Meng and C. Zhang, ACS Nano, 2014, 8, 8121-8129. 
6 A. Laursen, K. Patraju, M. Whitaker, M. Retuerto, T. Sarkar, N. Yao, K. Ramanujachary, M. Greenblatt and G. Dismukes, Energy Environ. Sci., 2015, 8, 1027-1034.

7 X. Wang, Y. V. Kolen'ko, X. Q. Bao, K. Kovnir and L. Liu, Angew. Chem., Int. Ed., 2015, 54, 8188-8192.

8 Y. Pan, N. Yang, Y. Chen, Y. Lin, Y. Li, Y. Liu and C. Liu, J. Power Sources, 2015, 297, 45-52.

9 Z. Cai, X. Song, Y. Wang and X. Chen, ChemElectroChem, 2015, 2, 1665-1671.

10 J. Li, J. Li, X. Zhou, Z. Xia, W. Gao, Y. Ma and Y. Qu, ACS Appl. Mater. Interfaces, 2016, 8, 10826-10834.

11 X. Wang, W. Li, D. Xiong, D. Y. Petrovykh and L. Liu, Adv. Funct. Mater., 2016, 26, 4067-4077.

12 N. Jiang, B. You, M. Sheng and Y. Sun, ChemCatChem, 2016, 8, 106-112.

13 B. You, N. Jiang, M. Sheng, M. W. Bhushan and Y. Sun, ACS Catal., 2016, 6, 714-721.

14 E. J. Popczun, C. G. Read, C. W. Roske, N. S. Lewis and R. E. Schaak, Angew. Chem., Int. Ed., 2014, 53, 5427-5430.

15 J. Tian, Q. Liu, A. M. Asiri and X. Sun, J. Am. Chem. Soc., 2014, 136, 7587-7590.

16 P. Jiang, Q. Liu, C. Ge, W. Cui, Z. Pu, A. M. Asiri and X. Sun, J. Mater. Chem. A, 2014, 2, 14634-14640.

17 Q. Liu, J. Tian, W. Cui, P. Jiang, N. Cheng, A. M. Asiri and X. Sun, Angew. Chem., Int. Ed., 2014, 126, 6828-6832.

18 Z. Pu, Q. Liu, P. Jiang, A. M. Asiri, A. Y. Obaid and X. Sun, Chem. Mater., 2014, 26, 4326-4329.

19 F. H. Saadi, A. I. Carim, E. Verlage, J. C. Hemminger, N. S. Lewis and M. P. Soriaga, J. Phys. Chem. C, 2014, 118, 29294-29300.

20 Q. Li, Z. Xing, A. M. Asiri, P. Jiang and X. Sun, Int. J. Hydrogen Energy, 2014, 39, 16806-16811.

21 H. Du, Q. Liu, N. Cheng, A. M. Asiri, X. Sun and C. M. Li, J. Mater. Chem. A, 2014, 2, 14812-14816.

22 Z. Huang, Z. Chen, Z. Chen, C. Lv, M. G. Humphrey and C. Zhang, Nano Energy, 2014, 9, 373-382.

23 E. J. Popczun, C. W. Roske, C. G. Read, J. C. Crompton, J. M. McEnaney, J. F. Callejas, N. S. Lewis and R. E. Schaak, J. Mater. Chem. A, 2015, 3, 5420-5425.

24 J. F. Callejas, C. G. Read, E. J. Popczun, J. M. McEnaney and R. E. Schaak, Chem. Mater., 2015, 27, 3769-3774.

25 L. Li, X. Li, L. Ai and J. Jiang, $R S C A d v$, 2015, 5, 90265-90271.

26 J. A. Vigil and T. N. Lambert, RSC Adv., 2015, 5, 105814.

27 N. Jiang, B. You, M. Sheng and Y. Sun, Angew. Chem., Int. Ed., 2015, 54, 6251-6254.

28 B. You, N. Jiang, M. Sheng, S. Gul, J. Yano and Y. Sun, Chem. Mater., 2015, 27, 7636-7642.

29 M. Liu and J. Li, ACS Appl. Mater. Interfaces, 2016, 8, 2158-2165.

30 Y. Pan, Y. Lin, Y. Chen, Y. Liu and C. Liu, J. Mater. Chem. A, 2016, 4, 4745-4754.

31 H. Huang, C. Yu, J. Yang, C. Zhao, X. Han, Z. Liu and J. Qiu, ChemElectroChem, 2016, 3, 719-725.

32 Y. Tan, H. Wang, P. Liu, C. Cheng, F. Zhu, A. Hirata and M. Chen, Adv. Mater., 2016, 28, 2951-2955.
33 D.-H. Ha, B. Han, M. Risch, L. Giordano, K. P. C. Yao, P. Karayaylali and Y. Shao-Horn, Nano Energy, 2016, DOI: 10.1016/j.nanoen.2016.04.034.

34 J. F. Callejas, J. M. McEnaney, C. G. Read, J. C. Crompton, A. J. Biacchi, E. J. Popczun, T. R. Gordon, N. S. Lewis and R. E. Schaak, ACS Nano, 2014, 8, 11101-11107.

35 P. Jiang, Q. Liu, Y. Liang, J. Tian, A. M. Asiri and X. Sun, Angew. Chem., Int. Ed., 2014, 53, 12855-12859.

36 Y. Yan, B. Y. Xia, X. Ge, Z. Liu, A. Fisher and X. Wang, Chemistry, 2015, 21, 18062-18067.

37 C. Lv, Z. Peng, Y. Zhao, Z. Huang and C. Zhang, J. Mater. Chem. A, 2016, 4, 1454-1460.

38 C. Y. Son, I. H. Kwak, Y. R. Lim and J. Park, Chem. Commun., 2016, 52, 2819-2822.

39 J. Tian, Q. Liu, N. Cheng, A. M. Asiri and X. Sun, Angew. Chem., Int. Ed., 2014, 53, 9577-9581.

40 P. Xiao, M. A. Sk, L. Thia, X. Ge, R. J. Lim, J.-Y. Wang, K. H. Lim and X. Wang, Energy Environ. Sci., 2014, 7, 2624-2629.

41 J. M. McEnaney, J. C. Crompton, J. F. Callejas, E. J. Popczun, A. J. Biacchi, N. S. Lewis and R. E. Schaak, Chem. Mater., 2014, 26, 4826-4831.

42 Z. Xing, Q. Liu, A. M. Asiri and X. Sun, Adv. Mater., 2014, 26, 5702-5707.

43 C. Deng, F. Ding, X. Li, Y. Guo, W. Ni, H. Yan, K. Sun and Y.-M. Yan, J. Mater. Chem. A, 2016, 4, 59-66.

44 Z. Yao, Y. Su, C. Lu, C. Yang, Z. Xu, J. Zhu, X. Zhuang and F. Zhang, New J. Chem., 2016, 40, 6015-6021.

45 Z. Pu, S. Wei, Z. Chen and S. Mu, Appl. Catal., B, 2016, 196, 193-198.

46 J. M. McEnaney, J. C. Crompton, J. F. Callejas, E. J. Popczun, C. G. Read, N. S. Lewis and R. E. Schaak, Chem. Commun., 2014, 50, 11026-11028.

47 T. Erdey-Gruz and M. Volmer, Z. Phys. Chem. A, 1930, 150, 203.

48 J. Heyrovský, Recl. Trav. Chim. Pays-Bas, 1927, 46, 582-585.

49 J. Tafel, Z. Phys. Chem., 1905, 50, 641.

50 J. K. Nørskov, T. Bligaard, A. Logadottir, J. R. Kitchin, J. G. Chen, S. Pandelov and U. Stimming, J. Electrochem. Soc., 2005, 152, J23-J26.

51 G. Kresse and J. Furthmüller, Phys. Rev. B: Condens. Matter Mater. Phys., 1996, 54, 11169-11186.

52 P. E. Blöchl, Phys. Rev. B: Condens. Matter Mater. Phys., 1994, 50, 17953-17979.

53 J. P. Perdew, K. Burke and M. Ernzerhof, Phys. Rev. Lett., 1996, 77, 3865-3868.

54 W. Tang, E. Sanville and G. Henkelman, J. Phys.: Condens. Matter, 2009, 21, 084204.

55 C. Campaná, B. Mussard and T. K. Woo, J. Chem. Theory Comput., 2009, 5, 2866-2878.

56 J. Rogal and K. Reuter, Experiment, Modeling and Simulation of Gas Surface Interactions for Reactive Flows in Hypersonic Flights, 2007, pp. 2-1-2-18.

57 D. R. Stull and H. Prophet, JANAF thermochemical tables, DTIC Document, 1971.

58 S. Rundqvist, Acta Chem. Scand., 1962, 16, 287-292.

59 Q. Tang and D. E. Jiang, ACS Catal., 2016, 6, 4953-4961. 